\title{
Osvrt na hercegovačko vinogradarstvo 20. stoljeća
}

\section{Sažetak}

Uzgoj vinove loze u Hercegovini ima izrazito dugu tradiciju. Svako stoljeće imalo je specifičan utjecaj na vinogradarstvo spomenutog podneblja, od čega 20. stoljeće najveći. Tijekom 20. stoljeća površine pod vinogradima intenzivno su se mijenjale, u proizvodnju su se uvodili novi kultivari te su se pojavljivali do tada nepoznati štetni organizmi. Razvoj kemijske industrije, primjena umjetnih gnojiva, formiranje državnih rasadnika, zadruga i poljoprivrednih kombinata imali su snažan utjecaj na vinogradarstvo u Hercegovini. Ovim radom predočit će se značajnije aktivnosti i događanja koja su obilježila uzgoj vinove loze tijekom prošlog stoljeća.

Ključne riječi: uzgoj vinove loze, Hercegovina, 20. stoljeće

\section{Uvod}

U Bosni i Hercegovini preko 95 \% površina pod vinovom lozom nalazi se upravo u južnim krajevima Hercegovine (Rotim i sur., 2017). Naime, podneblje Hercegovine odlikuju iznimno povoljni uvjeti za uzgoj vinove loze i proizvodnju vina visoke kakvoće. I pored toga, tek nakon Austrougarske okupacije ovih prostora razvoju vinogradarstva i vinarstva posvećena je veća pozornost. Čak što više, početak 20. stoljeća smatra se zlatnim dobom hercegovačkog vinogradarstva. Uostalom, 1912. godine ukupne površine pod vinovom lozom iznosile su rekordnih 6.040 ha. Nažalost, pojava filoksere i teške ekonomske posljedice koje je ostavio Prvi svjetski rat zaustavili su progresivni razvoj vinogradarstva. Uslijedila je gospodarska stagnacija koja je uz agrarnu krizu utjecala i na vinogradarski sektor, a hercegovački težak je zbog učestalih sušnih razdoblja bio suočen s velikom oskudicom. Stoga ne čudi podatak kako je dvije trećine radnog svijeta svake godine prilikom berbe kukuruza odlazilo u Slavoniju, da bi za to vrijeme teškog i mukotrpnog rada zaradilo 5-6.000 kg kukuruza, a sve kako bi svoju obitelj za 2 do 3 mjeseca opskrbili palentom (Jugoslavenski list, 1937). Po završetku svjetskog rata, u razdoblju 1922.1928. godine izvršena je prva obnova vinograda, da bi uskoro sve aktivnosti prekinuo Drugi svjetski rat. Novi, značajniji pokušaj obnove hercegovačkih vinograda zabilježen je u razdoblju 1957.-1961. godine, nakon čega dolazi do stvaranja prvih poljoprivrednih kombinata i jačanja društvenog sektora. Zbog brojnih ratova, pojave filoksere, agrarnih kriza i reformi te različitih sustava vlasti koje su se smjenjivale na ovom prostoru, 20. stoljeće će u povijesti vinogradarstva ostati upamćeno kao najzanimljivije doba u njegovoj tisućljetnoj tradiciji.

\section{Formiranje prvih zadruga}

Početkom 20. stoljeća na području Hercegovine osnivaju se prve seljačke zadruge. Prva zadruga u Hercegovini osnovana je 5. kolovoza 1906. godine u Nevesinju i zvala se „Hrvatska seljačka zadruga za štednju i zajmove sa ograničenim jamstvom u Nevesinju“. Osnivanju su nazočila 34 zadrugara, a u ime mjesne vlasti prisutan je bio kotarski poglavar Arthur pl. Marczell (AZV, 1906). Bitno je istaknuti kako su prvih godina razvoja zadrugarstva sve osnovane zadruge 
imale nacionalni predznak. $U$ to doba zadruge su uglavnom osnivali obrazovani ljudi, većinom svećenici i učitelji. Uskoro je zadaću za širenje zadrugarske ideje u Bosni i Hercegovini na sebe preuzela Hrvatska Narodna Zajednica. Koncem 1919. godine postojeće zadruge osnivaju svoj Savez hrvatskih seljačkih zadruga u Sarajevu koji je preuzeo na sebe dužnost organizacije, financiranja i revidiranja zadruga. Savez je 1927. godine brojio 96 zadruga sa okruglo 15.000 zadrugara pa je zadrugarstvo predstavljalo najvažniji gospodarski i kulturni čimbenik među hrvatskim seljačkim svijetom u Bosni i Hercegovini (Lisac, 1927) A prvi registrirani oblik udruživanja vinogradara predstavljalo je Vinogradarsko dioničko društvo u Trebinju osnovano 1909. godine. Društvo je, kako piše u pravilima društva, osnovano radi osiguranja bolje cijene grožđa i unapređenja vinogradarstva (Beljo i sur., 2018). Iste godine, ukupno je osnovano šest zadruga, a među njima i Prva hercegovačka vinarska zadruga sa sjedištem u Mostaru (kasnije Vinogradarsko dioničko društvo Mostar). Godine 1924. vinogradari Čitluka formiraju Hrvatsku seljačku vinogradarsku zadrugu, dok su vinogradari Konjica svoju zadrugu osnovali 1930. godine (Hadžiomerović, 1987). Godine 1956. na području Mostara djeluju 84 zadruge od čega se članovi 56 zadruga bave vinogradarstvom. Od ukupne obradive površine koju zadruge posjeduju i obrađuju 37,1 \% otpada na vinograde (Džeba, 1957). Sedamdesetih godina prošlog stoljeća dolazi do velikih promjena u hercegovačkom zadrugarstvu čemu je pridonijela migracija sa sela, kao početak deagrarizacije što najbolje svjedoči podatak kako je 1975. godine djelovalo samo osam zadruga. Broj zadruga se smanjivao dok su primat preuzimali veliki poljoprivredni kombinati koji su sve snažnije utjecali na individualnu poljoprivrednu proizvodnju otvarajući na taj način mjesto zadrugama da se integriraju (Hadžiomerović, 1987).

\section{Površine pod vinogradima}

Godine 1913. nalazilo se u Hercegovini pod vinogradima ukupno 5.817 ha. Površine pod vinovom lozom razlikovale su se od samog lokaliteta uzgoja te su gledano po hektarima iznosile u kotaru: Mostarskom 3.148 ha, Ljubuškom 825 ha, Stolačkom 678 ha, Konjičkom 653 ha, Trebinjskom 500 ha i Ljubinskom 13 ha. S druge strane, u cijeloj Hercegovini bilo je 1925. pod vinovom lozom, što pod starom, što pod američkom 3421.40 ha (Lovrenović, 1929). Slične podatke prezentirao je i dr. Rade Smoljan navodeći kako je pod vinogradima 1913. godine bilo oko 6.000 ha zemljišta dok se pod vinogradima 1926. nalazilo oko 2.500 ha, što je manje za 3.500 ha ili $58 \%$ (Smoljan, 1928).

Tablica 1. Površine pod vinogradima na području Hercegovine

Table 1. Areas under vineyards in Herzegovina

\begin{tabular}{cc}
\hline Godina/Year & Površine pod vinogradima (ha)/ Areas under vineyards(ha) \\
\hline 1912. & 6.040 \\
\hline 1913. & 5.817 \\
\hline 1922. & 4.605 \\
\hline 1928. & 2.408 \\
\hline 1931. & 2.506 \\
\hline 1940. & 3.476 \\
\hline 1945. & 3.021 \\
\hline 1952. & 3.454 \\
\hline 1971. & 5.098 \\
\hline 1980. & 4.856 \\
\hline 1991. & 5.792 \\
\hline
\end{tabular}


Godine 1985. godine površine pod vinovom lozom dosegle su veličinu od oko 5.800 ha, s tim da se u društvenom sektoru tada nalazilo više od 2.000 ha plantažnih vinograda (Smoljan, 1999).

\section{Pojava filoksere}

U Hercegovini se filoksera pojavila 1912. godine u selu Vinjani, u ljubuškom kotaru (Smoljan, 1997). U Dračevicama kod Mostara 1912. godine zapaženi su simptomi na lozi koji podsjećaju na zaraženost filokserom. Pretpostavka je bila da su je tu na motikama donijeli težaci koji su iz Dalmacije dolazili kopati lozu (Beljo i sur., 2018). Već u ožujku 1913. godine u kotaru Ljubuškome, a na granici hercegovačkoj konstatirana je filoksera na više mjesta. Zbog toga je Zemaljska vlada poduzela mjere i sredstva za ograničavanje njenog širenja. Tako je u Hercegovini bilo strogo zabranjeno prenositi sadni materijal iz jednog vinograda $u$ drugi dok se $u$ kotaru Ljubuški osim vinove loze ograničio prijenos i ostalih biljnih vrsta (Narod, 1913). Dakle, u Hercegovini je filoksera uočena neposredno pred Prvi svjetski rat, i to skoro dva desetljeća nakon što je evidentirana u Dalmaciji i od tada je stalno prisutna na ovim prostorima. Tijekom ratnih godina kada je zbog opće mobilizacije radno sposobno stanovništvo bilo odsutno iz rodnog kraja filoksera je uništila brojne površine pod vinogradima u Hercegovini. Osim toga, vlasti u to ratno doba nisu dopuštali da se uopće pristupa obnovi i saniranju vinograda. Tek u godinama nakon završetka Prvog svjetskog rata počinje masovna revitalizacija vinograda kojoj je prethodila kampanja educiranja vinogradara o novim trendovima uzgoja vinove loze. Stoga su lokalne vlasti organizirale brojne stručne skupove na kojima su se vinogradari upoznavali s novim trendovima u vinogradarstvu, osnivali su se državni lozni rasadnici, stimulirala se nabavka loznih cjepova, sve s ciljem obnove vinogradarske proizvodnje (Rotim, 2018). Međutim, bitno je napomenuti da je pred sam početak Prvog svjetskog rata u najugroženijim područjima od filoksere tadašnja vlast započela sa uspostavom i osnivanjem državnih rasadnika loznih podloga.

\section{Prvi Državni lozni rasadnici}

Nakon pojave filoksere na području Ljubuškog, koncem 1912. godine se u tom kotaru započelo sa uspostavljanjem prvog državnog loznog rasadnika. Predviđeni troškovi uspostave rasadnika iznosili su oko 20.000 kruna, a kraj radova planiran je do proljeća 1913. godine. Rasadnik je bio namijenjen za sadnju najotpornijih sorti američke loze koje su označene kao najpodesnije za područje Hercegovine. Planirano je da se sadni materijal nabavi kod već postojećih loznih rasadnika u Derventi i Bijeljini (Kršćanska obitelj, 1913). Međutim, za potrebe ovog rasadnika doneseno je iz loznog rasadnika u Čibači kod Dubrovnika 12.000 reznica različitih američkih vrsta loze. $U$ to vrijeme filoksera još nije bila došla do Dubrovnika. Rasadnik je bio lociran u selu Radišići kod Ljubuškog. U početku je imao površinu od 5,6 ha da bi se kasnijom kupovinom zemljišta površina povećavala tako da je do 1931. ukupna površina rasadnika iznosila 12 ha. Rasadnik u Ljubuškom bio je najvažniji rasadnik podloga u BiH i odigrao je značajnu ulogu u obnovi vinograda u Hercegovini (Beljo i sur., 2018). Spomenimo još kako je poljoprivredni stručnjak gosp. Andrija Kutuzov godine 1931. pokrenuo osnivanje novog sreskog rasadnika u Ljubuškom (Jugoslavenski list, 1931) te da je općinski lozni rasadnik u Trebinju osnovan već 1920. godine na površini od 0,5 ha, kao i općinski lozni rasadnik u Čitluku na površini od 0,18 ha. A u vrijeme pojave filoksere, pored onog u Ljubuškom, za drugi hercegovački rasadnik sorti američke loze određeno je zemljište kod Prve voćarske i vinogradarske stanice u Mostaru koja se nalazila na području Gnojnica kod Mostara. Spomenutoj stanici pripadao je i mostarski rasadnik „Radobolja“. Rasadnik se prostirao na površini od 20.000 četvornih metara, a njime je upravljao Antun Phildius, dok je vrtlarske poslove obavljao Karlo Ritzl (Glas Hercegovca, 1894). 
Rasadnik se nalazio u strogom centru grada, nekoliko stotina metara istočno od franjevačkog samostana i zbog širenja grada je premješten u Konjic. Slično se desilo s gradskim odnosno školskim rasadnikom koji se nalazio na samom kraju Bolničke ulice u Mostaru, a koji je prestao s radom oko 1906. godine. Godine 1956. na području Hercegovine nalazilo se 13 ha pod matičnjacima, s ukupnom godišnjom proizvodnjom 1.548 .000 reznica prve i druge klase. Osim toga, rasadnici su tih godina proizvodili 40.000 korijenaka i oko 80.000 ožiljenih loznih cjepova (Džeba, 1957). U hercegovačkom je vinogradarstvu posebno značenje imala proizvodnja loznih podloga u Popovu polju. Od predviđenih 150 ha matičnjaka loznih podloga u 1985. godini već je bio u funkciji kompleks od 75 ha. Taj se izvrsni sadni materijal za cijepljenje vinove loze izvozio najvećim dijelom u Njemačku, Italiju i Sovjetski Savez (Smoljan, 1999).

\section{Sortiment vinove loze}

Gledano za podneblje Hercegovine 1929. godine većina površina pod vinovom lozom nalazila se u kotaru Mostar. U to doba, od sveukupnih vinograda u mostarskom kotaru tri četvrtine činile su bijele sorte grožđa (Žilavka, Bena, Krkošija) dok je na sorte crnog grožđa (Blatina, Skadarka, Pošip crni, Alicante Boushet) otpadala jedna četvrtina (Lovrenović, 1929). Iza Drugog svjetskog rata pored gore navedenih evidentirano je preko četrdeset različitih sorata vinove loze koje su u vrlo malim postotcima sudjelovale u proizvodnji vina (Džeba, 1957). Dakle, pored već poznatih sorata u Hercegovini su se mogle pronaći i brojne druge, za naše podneblje tada novije sorte koje su se već bile pokazale kao pouzdane. Spomenute i u to doba manje poznate sorte nalazile su se u vinogradu Mehmed Alije Hadžića u Konjicu, u Banskom rasadniku u Biogradu na moru, u Banskom rasadniku u Ljubuškom te u manastirskom vinogradu u Žitomisliću. Iz spomenutih vinograda i rasadnika zainteresirani vinogradari nabavljali su plemke za cijepljenje. Osim toga, konstatirano je kako će za dvije do tri godine biti dovoljno plemki do sada najbolje stolne sorte Afus Ali, od koje se trenutno samo dva trsa nalaze u vinogradu g. Hadžića u Konjicu. Planirano je da se spomenuta stolna sorta tijekom proljeća 1930. godine razmnoži u manastirskom vinogradu u Žitomisliću, od kuda će se distribuirati plemke za njeno daljnje umnožavanje (Narodna sloboda, 1930). Od tada do danas sorta Afus ali je u Hercegovini prilično zastupljena u uzgoju, kako na velikim površinama tako, i na okućnicama. Zbog svog harmoničnog i osvježavajućeg okusa, ali i srednje otpornosti na bolesti i štetnike te dobre podnošljivosti transporta, taj se stolni kultivar ubraja među najcjenjenije na svijetu (Rotim i Gašpar, 2016).

\section{Izravno rodni hibridi}

Vinova loza koja se 1929. godine uzgajala u Hercegovini uglavnom je bila oplemenjena tj. cijepljena, dok su tzv. „direktori“ ili izravno rodni hibridi („francuska loza“ ili necijepljena loza francuskog porijekla) na ovom podneblju bili još uvijek nepoznati. Nasuprot Hercegovini, spomenutim, direktorima“ u znatnijoj mjeri bila je zaražena Slavonija, gdje se tih godina loza iskorjenjivala uz velike materijalne štete tamošnjih vinogradara. Neupućeni vinogradari, osobito oni manjih financijskih mogućnosti, kada bi doznali za vinovu lozu koju nije potrebno ni cijepiti, ni sumporati ni polijevati modrom galicom, a koja pored toga ostvaruje dobar urod, rado bi je posadili. Premda bi uzgoj takve vinove loze doveo do mnogih ušteda hercegovački vinogradari nisu je sadili. Naime, uvidjeli su kako je grožđe s takve loze slabije kakvoće, pri okusu zaudara na stjenicu (tzv. „čimavicu“) i daje loše vino, od koga kad se konzumira sutradan boli glava. Međutim, i pored tih saznanja doznalo se da je nekolicina seljaka u blizini Mostara za probu posadila izravno rodne hibride. Sakrili su ih od poljoprivrednih referenata, kako ih oni ne bi pronašli prilikom obilaska sela u svrhu gospodarske poduke naroda. Sreća je po hercegovačko vinogradarstvo da se takva pojava nije raširila jer bi ionako siromašan narod pretrpio velike 
štete naknadnim uništavanjem vinograda. Osim toga, od izravno rodnih hibrida prema nacrtu Zakona o vinu nije bilo dozvoljeno proizvoditi vino. U članku 13. spomenutog zakonskog nacrta predviđeno je da se od godine 1928. zabranjuje promet i prodaja takvih vina. Iznimno se dozvoljavala prodaja vina samo od onih „direktora“ čije razmnožavanje odobri ministar poljoprivrede i voda, shodno Zakonu o obnavljanju i unaprjeđenju vinogradarstva. Tih nekoliko vinovih loza uništilo se odmah, a sve kako loza pod nazivom,direktori“ u Hercegovini uopće ne bi bila poznata (Lovrenović, 1929).

\section{Početakprimjene umjetnih gnojiva}

Stajskog gnoja na području Hercegovine nikada nije bilo u dostatnim količinanama, a i kakvoća spomenutog gnoja često nije bila zadovoljavajuća. To su uočili i strukovni organi tadašnje vlasti koji su znali da se pokusi s umjetnim gnojivima već provode po raznim mjestima u Hrvatskoj i Slavoniji. Osim toga, Hrvatska je 1913. imala potrošnju umjetnih gnojiva u količini od 2.952 vagona, a 1929. godine ona je narasla na 6.676 vagona (Mandekić, 1935). Kako su pokusi s gnojivom u Hrvatskoj doveli do zavidnih rezultata ostvaren je kontakt s društvom „Foskfot“ d.d. iz Zagreba koje je tijekom proljeća 1930. godine u pokusne svrhe sreskom poljoprivrednom referentu u Mostaru uručilo 1.000 kg umjetnog gnojiva „Herkulesa“. Pokusi su provedeni kod dvadeset posjednika u srezu na raznim mjestima i po svim općinama, i to tako, da se mogao vidjeti učinak na svim glavnim kulturama, kao što su vinova loza, ozime žitarice, kukuruz, krumpir, krma, blitva i duhan. Umjetna gnojiva su primjenjivana nekoliko godina unatrag pa je tako upotreba gnojiva u 1927. godini iznosila 30-40 mtc., u 1928. 50-60 mtc., u 1929. do 100 mtc., da bi u godini 1930. potrošnja iznosila oko 35 vagona. Naravno da ovaj porast primjene nije došao sam od sebe, već stoga, što su ljudi došli do uvjerenja, da mu gnojivo djeluje ne samo na veći prihod, već i na bržu i bolju zriobu, čime se postiže i veća kakvoća te kvantiteta (Jugoslavenski list, 1930).

\section{Nestašica sumpora i modre galice}

Prvi svjetski rat u velikoj mjeri utjecao je na smanjenje površina pod vinogradima u Hercegovini. Kao što je poznato, upravo tada pojavila se filoksera da bi dolaskom rata radno sposobno stanovništvo bilo mobilizirano na ratišta. Osim toga, vinogradari su bili suočeni s nestašicom osnovnih pripravaka koji su se koristili za suzbijanje najznačajnijih biljnih bolesti - plamenjače i pepelnice. Tako je 1916. godine bilo nemoguće nabaviti potrebne količine sumpora za sumporanje vinograda. Sumpor je u to doba predstavljao jedino raspoloživo sredstvo za suzbijanje uzročnika pepelnice. U Hercegovinu se uvozio iz Sicilije i Sjeverne Amerike te zbog rata opskrba nije bila moguća. Stoga je u svrhu suzbijanja pepelnice ili kako se u narodu još zvala bijela maća, lug ili oidijum predloženo da se vinogradi tretiraju krečom. A kreč je kao sredstvo preporučen od strane tadašnjeg uglednog vinogradarskog lista „Neue Wiener Weinzeitung“. Sugerirano je da se po uočavanju bolesti grozdovi tretiraju tj. okupaju s rastopinom 3 \% kreča. Tretiranje je trebalo ponoviti najmanje dva puta. Kreč kao sredstvo oduzima bobicama grozda vlagu te se na taj način sprječava širenje bolesti, a kao alternativa navedeno je zaprašivanje grozdova sitno istučenim cimetom (Hrvatska narodna zajednica, 1916, broj 6).

$\mathrm{U}$ to ratno doba nedostajalo je i modre galice. Navodi se kako je 1915. bila izrazito loša vinogradarska godina jer je vladalo kišno vrijeme u vegetacije, a modra galica se nije mogla nabaviti. Vinogradi su oboljeli od plamenjače ili kako su bolest još zvali obična medljika, plijesan ili peronospora. Nestašica galice nastala je zbog toga što je vojnička uprava za svoje svrhe zaplijenila skoro cijelu zalihu, a ono malo što je ostalo za trgovinu raznim je špekulacijama poskočilo u cijeni (Hrvatska narodna zajednica, 1916, broj 3) I tijekom Drugog svjetskog rata došlo je do nestašice modre galice. Tada je Glavno ravnateljstvo izdalo posebnu okružnicu kojom upućuje 
vinogradare da će potrebnu modru galicu dobiti samo u zamjenu za bakar, broncu ili mjed, i to u omjeru: za svaki kilogram čistog bakra 3,5 kg modre galice. Kod bronce i mjedi ovaj omjer biti će manji radi primjese drugih kovina (Kršćanska obitelj, 1943). Spomenimo još kako se sumpor cijelo 20. stoljeće koristio u zaštiti vinograda. Naime, sumporanje vinove loze obavljalo se protiv pojave pepelnice dobro poznatim sredstvima sumporom i sumpornim preparatima, kao što su kosan i močivi sumpor. Prvo sumporanje obavljalo se odmah nakon kretanja vinove loze, a drugo pred cvatnju. Količina sumpora za tretiranje je bila veća nego kod prve primjene i iznosila je 25-30 kg po hektaru vinograda. Početkom osamdesetih godina sve češće se koristio u to vrijeme novi sistemični fungicid Bayleton (Sloboda, 1985, broj 20).

\section{Osnivanje Antiperonospornih službi}

Iza Drugog svjetskog rata organizirana je Antiperonosporna služba u Hercegovini. Organizirala ju je i njome rukovodila Rajonska stanica za zaštitu bilja u Mostaru. U sklopu ove službe formirana je Antiperonosporna služba u Čitluku kod Mostara, s ciljem prikupljanja i obrade potrebnih meteoroloških podataka i praćenja razvoja plamenjače. Na osnovu prikupljenih podataka određivali bi se optimalni rokovi tretiranja vinograda na ovom području. Meteorološki instrumenti bili su postavljeni u vinogradu ZZ Čitluk čija površina je iznosila 20 ha, dok je cijelo broćansko vinogorje raspolagalo s preko 1.000 ha vinogradarskih površina. U obližnjim selima Međugorju i Tepčićima bile su postavljene kišomjerne stanice koje su imale zadatak stanici u Čitluku dostavljati podatke o padalinama na tom području. Na temelju podataka o padalinama i temperaturi određivani su rokovi tretiranja u svrhu zaštite vinograda od plamenjače. Stanica je s radom i prikupljanjem meteoroloških podataka počinjala 20. travnja da bi rad za tekuću sezonu završavala 31 srpnja. U godinama povoljnim za razvoj bolesti, a to su jako kišne godine s obilnim rosama u jutarnjim satima plamenjača je znala pričiniti katastrofalne štete. $S$ druge strane, u sušnim godinama bespotrebno su se koristile iznimno velike količine plavog kamena i kreča tako da se za samo jedno tretiranje svih vinograda u Hercegovini trošilo preko 4 vagona plavog kamena, što je predstavljalo sumu od oko 10.000 .000 dinara. Spomenimo još kako su pripremne aktivnosti za osnivanje spomenutih stanica započele još 1939. godine. Tako je Kraljevska banska uprava primorske banovine - Poljoprivredno odjeljenje iz Splita dana 18.03.1939. (dokument broj 4727/39) dostavila Banskoj poljoprivrednoj stanici u Mostaru referat „Upute za uspostavu rada na antiperonosporičnim stanicama“. U dopisu se navodi kako je Kraljevska banska uprava u Splitu već poduzela korake da se na vrijeme pribave potrebiti uređaji za antiperonospornu stanicu koja će se uspostaviti pri tamošnjoj ustanovi. Godine 1956. postojale su Antiperonosporne službe u Mostaru, Ljubuškom, Čapljini, Domanovićima i Lastvi.

\section{Doba poljoprivrednih kombinata}

Poljoprivredni kombinat „Hercegovina“ poznatiji pod skraćenicom HEPOK nastao je 1966. godine. U razdoblju između 1966. i 1972. godine dvadesetak organizacija iz poljoprivredne oblasti udružilo se u HEPOK, koji se sve više širio po Hercegovini. Godine 1980. HEPOK je imao 4.200 uposlenih, a udruženo je bilo oko 1.200 poljoprivrednih proizvođača i oko 4.000 kooperanata. U njegovu sastavu bili su gotovo svi $(98,8 \%)$ vinogradi (Smoljan, 1999). Kasnije je u Mostaru 26. prosinca 1980. godine osnovan SOUR APRO Hercegovina koji je predstavljao poljoprivredni, proizvodni, prometni, turistički i ugostiteljski kombinat. Nastao je udruživanjem HEPOK-a (agroindustrija), HIT-a (trgovina) i HETMOS-a (ugostiteljstvo i turizam). O kakvom se gigantu radilo najbolje svjedoči podatak kako je maloprodajnu mrežu SOUR-a APRO činilo blizu 800 objekata, od modernih robnih kuća, supermarketa, specijaliziranih trgovina koji su svakodnevno opskrbljivali oko 700.000 potrošača ponudom koju je činilo 40.000 različitih artikala. Veliki dio svog proizvodnog programa APRO je usmjerio na svjetsko tržište. Tako je vanjskotr- 
govinsku razmjenu ostvarivao sa 37 inozemnih tvrtki iz 28 zemalja i s pet kontinenata. Izvoznu paletu činilo je 15 proizvoda sa znakom APRO. Čitav proizvodni program vodio je vlastiti Istraživačko-razvojni institut (IRC) iz kojeg su potekli svi razvojni programi temeljeni na provjerenim znanstvenim i stručnim analizama. Dok je još djelovao u sklopu HEPOK-a IRC je poduzeo aktivnosti na zaštiti podrijetla Žilavke i Blatine koje su proglašene čuvenim hercegovačkim vinima. Proizvodnja Žilavke je zaštićena 1970., a Blatine 1973. godine. Godine 1985. APRO je raspolagao sa 60.000 ha zemljišnih površina, 2.500 ha vinograda i voćnjaka, 26 ha staklenika i plastenika, 2 farme muznih krava, 4 planinske farme, 2 peradarske farme, 15.200 četvornih metara ribnjaka, tvornicom stočne hrane, 3 klaonice, 2 mljekare, 4 vinarije, destilerijom, tvornicom za preradu voća, mlinovima i silosima za žito i s još mnogo toga (Sloboda, 1985, broj 1 i 2 ).

Progresivan razvoj vinogradarstva sredinom osamdesetih godina usporila je tadašnja vinska kriza koja se osjetila i u Hercegovini. Stoga nitko u APRO sustavu nije podizao nove nasade vinove loze izuzev mostarskih plantažera. Tako su vinogradari „Plantaže Mostar“ na lokalitetu Željuša zaokružili proizvodnu cjelinu od 400 ha, a tijekom jeseni 1985. u proizvodnju je ušlo 167 ha sa Žilavkom i Smederevkom. Očekivan je prinos od 1.800 tona grožđa, što je izvanredan urod za vinovu lozu staru četiri i pet godina. Plantaža „Željuša“ je u tom trenutku bila jedina kompletna APRO plantaža sa svim što je bilo potrebno tj. sustavom za natapanje, objektima društvenog standarda, strojnim prostorom i parkom, kao i pistom za korištenje poljoprivrednog zrakoplovstva. Pored toga na lokalitetu,Kosor“ na mjestu starog nasada bresaka površine 110 ha postupno se podizao novi nasad Žilavke. Tijekom proljeća 1985. godine, nakon trogodišnjeg odmora parcela, već je na spomenutom lokalitetu i na površini od 55 ha bilo posađeno oko 140.000 cjepova najčuvenije hercegovačke vinove loze Žilavke. Tijekom jesen na ovoj novoj plantaži biti će ukupno zasađeno oko 300.000 sadnica (Sloboda, 1985, broj 17).

\section{Elementarna nepogoda u 1985. godini}

Godina 1985. neće ostati u lijepom sjećanju hercegovačkih vinogradara. Naime u razdoblju od siječnja do svibnja vinovoj lozi velike su štete načinile ekstremno niske temperature, grad i kasni proljetni mrazevi. Tako su tijekom siječnja 1985. godine, kao stoljetni izuzetak, na području Ljubinja zabilježene rekordno niske temperature od $-26^{\circ} \mathrm{C}$, području Stoca (Poplat) $-22^{\circ}$ C, Mostara od $-19^{\circ} \mathrm{C}$ i području Čapljine od $-16^{\circ} \mathrm{C}$. Od sortimenta vinove loze najveća oštećenja uočena su na stolnim sortama: Kardinal, Kraljica vinograda i Afus ali, dok je od vinskih sorata velika oštećenja pretrpio Vranac. Najviše je oštećenih trsova uočeno u vinogradima koji su se nalazili pored rijeka i u depresijama. Osim izravnih šteta u pogledu izmrzavanja cijelih trsova i gubitka prinosa u 1985. godini došlo je do djelomičnog oštećenja rodnih elemanata na vinovoj lozi kojoj je trebalo dvije do tri godine da se regenerira odnosno podmladi. Kao posljedica niskih zimskih temperatura 1985 . godine iskrčena je kompletna tendona od 20 ha koja se nalazila na lokalitetu Dračevice kod Mostara. Iste godine na pojedinim područjima došlo je do pojave grada (Čitluk i Mostar) te kasnih proljetnih mrazeva (slana) koji su također izazvali oštećenja u nasadima vinove loze.

\section{Literatura}

Akti Zemaljske vlade (AZV), 4 279/HB, Arhiv Bosne i Hercegovine, 1906. Sarajevo.

Beljo, J., Bašić, Ž., Blesić. M., Dragić, B., Ivanković, M., Jovanović-Cvetković Tatjana, Leko, M., Mijatović, D., Pediša, H., Prusina, T., Vaško, Ž. (2018) 130 godina organiziranog vinogradarstva i vinarstva u Bosni i Hercegovini, Mostar: Federalni agromediteranski zavod Mostar i Agronomski i prehrambeno-tehnološki fakultet Sveučilišta u Mostaru, str. 148.

Džeba, H. (1957) Vinogradarstvo i vinarstvo Hercegovine, Diplomski rad, Beograd: Ekonomski fakultet.

Hadžiomerović, M. (1987) Osamdeset godina zemljoradničkog zadrugarstva u Hercegovini, Nevesinje: Apro-Zemljoradnička zadruga Nevesinje.

Hrvatska narodna zajednica: Polijevanje loze protiv plamca (peronospore), broj 3., 31.03.1916., god IV, str. 36. i 37., Sarajevo. 
Hrvatska narodna zajednica: Sumporanje vinograda, broj 6., 30.06.1916., god IV, str. 93. i 94., Sarajevo.

Glas Hercegovca: Cjepiljnjak-Radobolja, broj 12., 28.02.1894., god XI, str. 3., Mostar.

Jugoslavenski list: Uspjeli pokusi sa umjetnim gnojivima u mostarskom srezu, broj 282., 06.12.1930., god XIII, str. 3., Sarajevo.

Jugoslavenski list: Osnivanje novog sreskog rasadnika, 15.02.1931., god XIV, str. 4., Sarajevo.

Jugoslavenski list: Široki Brijeg, broj 162., 13.07.1937., god XX, str. 4., Sarajevo.

Kršćanska obitelj-poučni i zabavni list za hrvatski katolički puk: Filoksera u hercegovačkom vinogradarstvu, god XIV, broj 7., 1. srpanj 1913., str. 162., Mostar.

Kršćanska obitelj-za vjerski odgoj i prosvjetu hrvatskog katoličkog naroda: Vinogradari pozor!, god XXVI, broj 4., travanj 1943., str. 65., Mostar.

Lisac, H. (1927) Razvitak hrvatskog seljačkog zadrugarstva u Bosni i Hercegovini. Napredak-Glasilo hrvatskog kulturnog društva Napredak u Sarajevu, 4 (2): 49.

Lovrenović, M. (1929) Proizvodnja vina u Hercegovini. Napredak-Glasilo hrvatskog kulturnog društva Napredak u Sarajevu, 4 (1-2): 8-9.

Mandekić, V. (1936) Razvoj narodnog gospodarstva zadnjih 75 godina, u: Obzor -spomen knjiga 1860.-1935., Zagreb:,Tipografije“ d.d., str. 213.-221.

Narod: Filoksera u hercegovačkom vinogradarstvu, broj 300., 29.05.1913., god IV, str. 3., Sarajevo.

Narodna sloboda-Glasilo Hrvatske pučke stranke za Hercegovinu: Vinogradari!, broj 10., 13.03.1930., god XII, str.

3., Mostar.

Rotim, N., Gašpar, M. (2016) Stolni kultivari vinove loze u Hercegovini. Glasnik zaštite bilja, 39 (5) 30-36.

Rotim, N., Gašpar, M., Perić, I. (2017) Vinski kultivari vinove loze u Hercegovini, Glasnik zaštite bilja, 40 (5): $78-85$.

Rotim, N. (2018) Filoksera ili trsov ušenac (Viteus vitofoliae Fitch). Glasnik zaštite bilja, 61 (6): 77-82.

Sloboda: Četiri godine SOUR-a APRO, broj 1. i 2., 1 i 7.1.1985., god XLI, str. 23., Mostar.

Sloboda: Žilavka na mjestu, broj 17., 22.04.1985., god XLI, str 7., Mostar

Sloboda: Vrijeme drugog sumporanja, broj 20., 13.05.1985., god XLI, str. 7., Mostar.

Smoljan, R. (1928) Može li se Hercegovini pomoći?. Jugoslavenski list, 11 (85): 17.

Smoljan, V. (1997) Poglavlja iz ekonomske historije Hercegovine Il., Mostar: Gospodarska komora Herceg-Bosne.

Smoljan, V. (1999) Poglavlja iz ekonomske historije Hercegovine IV., Mostar: Gospodarska komora Herceg-Bosne.

Prispjelo/Received: 22.8.2020.

Prihvaćeno/Accepted: 29.9.2020.

Review paper

\title{
Review of 20th century wine-growing in Herzegovina
}

\begin{abstract}
Herzegovina has a very long tradition of wine-growing. Every century had its specific impact of winegrowing in the mentioned region, however the 20th century affected it most strongly. In the 20th century the vineyard areas intensively changed, new sorts were introduced, and new until then unknown pests appeared. The development of chemical industry, application of artifical fertilizer, establishing state nursery-gardens, cooperatives and agri-businesses had a strong impact on Herzegovinian wine-growing. This papper will present the important activities and events that characterized wine-growing in the last century.

Key words: wine-growing, Herzegovina, the 20th century
\end{abstract}

